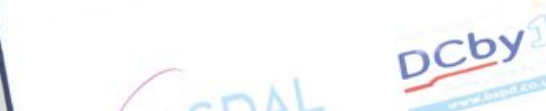

NDentalElite $d @ d d \& c 0$

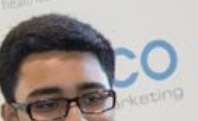

\section{Tiny tots bring great benefits to the Maltings}

The Maltings Dental Practice in Grantham was the winner of the inaugural Dental Check by One Practice of the Year award. Sponsored by NASDAL, the award recognises the practice that has most successfully introduced Dental Check by One. Created by the British Society of Paediatric Dentistry, the aim of the Dental Check by One campaign is to increase the number of children who access dental care aged 0-2 years.

The award is important as it illustrates the fact that doing the right thing is the right decision from a business perspective. The Maltings has supported Dental Check by One since it was launched. In the first few months they welcomed an additional 50 under twos to the practice.

The award was presented by Chief Dental Officer Sara Hurley at BDIA Showcase. Also present was the Chairman of NASDAL, Nick Ledingham (right) and Claire Stevens (left), spokesperson for BSPD.

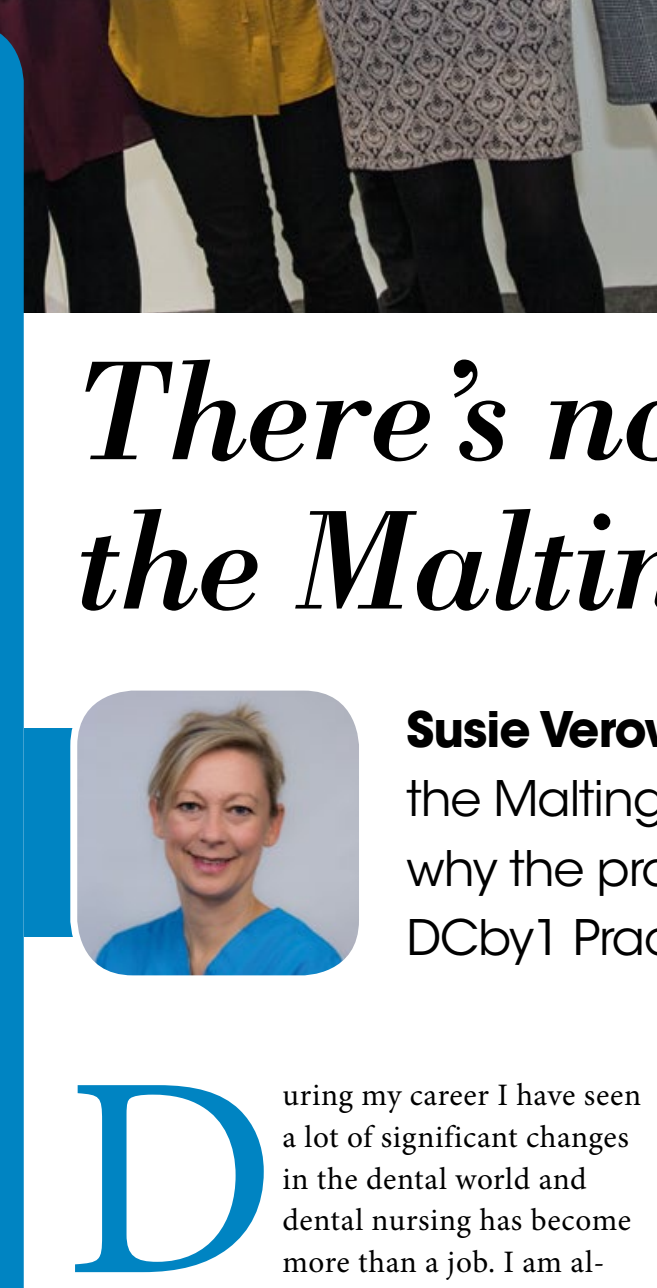

ways enthusiastic and passionate to provide the best care to my patients.

At the practice my roles include general dental nursing, working with visiting oral

Susie has worked at The Maltings Dental Practice in Grantham, Lincolnshire for 10 years, and has been a dental nurse since 1992. surgeons within the practice, as well as running my own clinics which include $\mathrm{x}$-ray taking, promoting better oral health and disease prevention. Disease prevention is a key part of the practice ethos and patients are routinely offered an appointment to provide them with oral hygiene education. Within these clinics I also provide the application of topical fluoride.

I am proud to be a member of The Maltings Dental Practice team, as we thrive on putting our patients' best interests first, with prevention being at the forefront. We regularly have team meetings to gather ideas on how to promote prevention and learn how we 